\title{
Possibilities and limitations of titanium alloy additive manufacturing
}

\author{
Anton Agapovichev ${ }^{1, *}$, Anton Sotov ${ }^{1}$, Victoria Kokareva ${ }^{1}$, and Vitaly Smelov ${ }^{1}$ \\ ${ }^{1}$ Samara State Aerospace University (National Research University), 443086 Moskovskoe sh. 34, \\ Russia
}

\begin{abstract}
This paper reviews the state-of-the-art of an important, rapidly emerging, additive manufacturing technology. Paper deals with the literature review of the Medical and Aerospace application of Additive Manufacturing from Ti alloys and its benefits and limitations. The study also demonstrate and compare the mechanical properties of Ti6Al4V samples produced by different technologies.
\end{abstract}

\section{Introduction}

Additive Manufacturing (AM) is defined by ASTM (standard F2792.1549323-1) as «process of joining materials to make objects from 3D model data, usually layer upon layer, as opposed to subtractive manufacturing technologies» [1]. AM is often described as the next step of the industrial revolution.

The efforts to drive the AM into manufacturing applications is direct to the industrial or production market, which includes medical, aerospace, automotive, and power generation; and the consumer market, which includes home accessories, fashion, and entertainment.

AM of titanium parts is also focusing on parts with high buy-to-fly ratio (the weight of the originally purchased stock material to the weight of the final finished part) for reducing the input weight of titanium. Typical aerospace components can have buy-to-fly ratio of 10:1 or 20:1 in some cases of conventional manufacturing processes. AM can reduce this ratio significantly and make it close to $1: 1$, moreover the machining time reduces.

Titanium and its alloys are not only expensive, but also difficult to machine using traditional manufacturing methods resulting in high manufacturing costs. AM offers a unique opportunity by reducing the raw material requirements as well as the extent of required post-machining operations.

In general, titanium alloys are used to produce a wide range of industrial components, including blades, fasteners, rings, discs, hubs and vessels. Titanium alloys are also used to produce high-performance race engine parts like gearboxes and connecting rods. Like cobalt chrome, titanium's biocompatibility makes the metal a viable option for medical applications, particularly when direct metal contact with tissue or bone is a necessity.

In AM, the mechanical properties of titanium alloys Ti6Al4V make them popular choices. Ti6Al4V is a titanium alloy that is 6 percent aluminum and 4 percent vanadium. It maintains its high tensile strength even at extreme temperatures. It is a grade-5, alpha-beta

\footnotetext{
* Corresponding author: agapovichev5@mail.ru
} 
alloy widely used in the fabrication of titanium parts. It is also weldable and heat-treatable. This low-density, high-strength metal also offers excellent corrosion resistance.

Due to rapid cooling of the metal melt pools, Ti6Al4V parts exhibit a fine-grained, dense microstructure that often exceeds that found in investment cast parts. Ti6Al4V is commonly used in offshore oil and gas extraction applications, where the metal alloy's extreme resistance to stress corrosion cracking in salt water is an advantage. The advanced metal alloy is also used in extremely demanding cryogenic and aerospace applications.

Unalloyed, commercially pure titanium is available in grades one through four. All grades exhibit extreme corrosion resistance, ductility and weldability, although Grade One is relatively more formable than Grades Two, Three and Four. Grade Four is the strongest.

Titanium Grade Two is a metal offering a desirable balance between formability and strength. It is used to create a wide variety of industrial parts, including those used in condenser tubing, heat exchangers, jet engines, airframes and marine chemical applications. Titanium Grade Two is also used in orthopedic prostheses and implants.

According to Levy and others, AM's benefits are depended from geometry complexity and mass production coefficient. [2]

Holmstrom distinguish the following advantages of AM technologies in comparison with conventional [3]:

- No tooling is needed significantly reducing production ramp-up time and expenses;

- Small production batches are feasible and economic. High production costs. Possibility to quickly change design;

- High rate of material utilization, up to $95 \ldots 97 \%$;

- Possibility to manufacture parts of complex form and configuration, including internal cavities, cellular structures for lightweight aircraft components;

Also AM technologies have some limitations:

- Requires post-processing operations ;

- Knowledge of AM processes and material is needed ;

- Limited component size/small production volumes.

Fraizer described the problems which we have to solve for AM aerospace industrial implementation [4]:

- Qualification and certification of materials. Development the integrated monitoring and control systems.

- Using of nondestructive inspection aids to identify defects with high probability.

- New design rules for AM parts development.

- Development of mathematical models that take into account all the physical features of the additive process for microstructure, mechanical and electrochemical properties prediction. The mathematical models allow to produce the materials with requirement mechanical behavior.

The conventional manufacturing is characterized by high cost and cycle time, steps of technological processes that are connection with huge number of tools and equipment. Additive manufacturing present a significant cycle time and cost reduction, tool-less fabrication, capability for novel designs no limited by manufacturing constraints.

\subsection{Ti alloys applications}

The most widespread titanium alloys that are used in additive industries, are alloys with alloying system titanium-aluminum vanadium type VT-6 (6Al-4V, Grade5, SAT-64, T$\mathrm{A} 6 \mathrm{~V}, \mathrm{Ti}-\mathrm{Al}-\mathrm{V})$ with an average aluminum content of $6 \%$ and vanadium $-4 \%$. Ti-6Al-4V is an $\alpha-\beta$ titanium alloy which is widely used in the aeronautical and medical fields thanks to its chemical and mechanical features (such as low density, high temperature specific strength, creep, oxidation and corrosion resistance) [5]. Titanium alloys are the most important of the advanced materials which are key to improved performance in additive 
manufacturing because of the excellent combinations of specific mechanical properties (low density) and good corrosion behavior.

Extensive implementation of AM titanium parts in aerospace and medical applications. Other applications for Ti AM include applications in chemical, defense and other industries. While selective laser melting (SLM) technology are suitable for smaller, complex form and geometries, with hollow unsupported structures, directed metal deposition (DMD) is better suited for larger parts with coarse features requiring higher deposition rates. Usage of finer powder grains combined with smaller laser/electron beam size leads to a superior surface finish on the as built parts.

The largest application of titanium metal is aerospace and defense industry. Therefore, the major direction of AM development is focused on weight savings through innovative designs that result in fuel savings and significant economic benefit during the service life of the aircraft.

The properties of the titanium alloy depend on the microstructure, the size and location of the $\alpha$ - and $\beta$-phases [6].

\subsubsection{Aerospace applications}

Currently, the major aerospace manufacturers such as Rolls-Royce, Airbus, Bombardier, Boeing, GE, Air Force Research Lab-US implement AM in civil and military aircraft and space vehicles applications.

Ti-6Al-4V is an attractive, lightweight material for spacecraft structures, as it provides an excellent combination of high strength, low density, high modulus, low coefficient of thermal expansion, and higher operational temperature than aluminum alloys.

Additive manufacturing holds significant potential for the aerospace industry, which requires parts that are lightweight, strong, and geometrically complex - and typically produced in small quantities. In order to reduce aircraft weight, the industry is developing a growing proportion of its parts from titanium. Aircraft landing gear, for example, can be additively manufactured from titanium layer by layer - rather than cut from a titanium block - thereby greatly reducing material waste and costs. In addition, additive manufacturing uses Ti-6Al-4V to create parts in geometries that may not be possible with conventional manufacturing. It can also significantly reduce the waste generated in producing the materials themselves, as well as in manufacturing and using the components [6].

Boeing, Inc., for example, has additively manufactured more than 200 different parts for 10 aircraft platforms. Boeing has also used roughly 20,000 additively manufactured parts in military and commercial aircraft, including 32 different components for its 787 Dreamliner planes. General Electric, the world's largest supplier of jet engines, is preparing to additively manufacture a fuel nozzle for use in thousands of jet engines. These nozzles are 25 percent lighter and as much as five times more durable than the existing model, which is welded from 20 different parts [10].. General Electric reports that it may additively manufacture up to half of the parts in its energy turbines and aircraft engines in 10 years.

Selective laser melting (SLM) is one of the most promising technologies that are being used in the aerospace sector. This process allows lightweight components design at a level that was not possible so far [8]. Antonysamy [9] approved that SLM allow producing lowlight parts with reducing $\mathrm{CO} 2$.

Recently, Matthew Tomlin and Jonathan Myer from EADS Innovations works have presented a study on the benefits of the AM using Arcam electron beam selective melting (EBSM) process for an Airbus A320 nacelle hinge bracket component. The original nacelle bracket is made of HC 101 steel and is produced through nearnet-shape sand casting and then machined to tolerance. The density of the original steel was $7.7 \mathrm{~g} / \mathrm{cm}^{3}$, whereas material Ti6Al4V is $4.42 \mathrm{~g} / \mathrm{cm}^{3}$, the materials optimised component weighed only $326 \mathrm{~g}$ compared to $920 \mathrm{~g}$ for the original component, giving a $64 \%$ reduction in weight. The 
ability to produce an optimised design geometry leads to a considerable amount of reduction in weight.

\subsubsection{Medical applications}

Titanium AM has good prospects in the medical markets (spine, hip, knee, and other orthopedic areas) due to bio-inertness and as-manufactured bone ingrowth performance.

AM allows a freedom of porosity, pore geometry cmlexity, relative density and surface roughness.

Sing et al. summarized the current progress of two additive manufacturing (AM) processes suitable for metallic orthopaedic implant applications : selective laser melting (SLM) and electron beam melting (EBM), additive manufactured biomaterials, such as Ti6Al4V and cobalt-chromium.

Tuomi [] classified the Additive Manufacturing application in medical into five major areas: medical models, surgical implant, surgical guides, external aids, biomanufacturing.

The significant developments made by Additive Manufacturing in the medical area is given below []:

- Creation of physical model, which gives better idea to doctors before performing procedures that helps surgeon.

- Substitute's bones fabricated by using Additive Manufacturing Technology and these substitutes' bones replaced defects areas.

- Improve strength of implants.

- Designing and development of medical implants.

- Reduction of operating time.

- Providing pre-surgical planning and also help medical students and surgeons.

- Producing lightweight implant.

- Reconstruction of skull/nose.

- Reconstructive surgery and aesthetic surgery.

- Used in improving quality of implants.

- Quickly created models in low cost.

In medical applications, SLM has strong perspective such as anatomically shaped implant manufacturing, biomedical devices, speed up surgical procedure especially complex surgeries, and implant placement.

Additive manufacturing is implemented for creating products according to patient's requirement, i.e., the customized implant builds quickly and with high accuracy at a reasonable cost.

There are several steps of process chain in medical application of Additive Manufacturing:

1) Medical diagnosis process (reverse engineering), imaging and scanning (MRI);

2) Preparing a data design of customized implants according to required shape;

3) The biomechanical simulation for patient needs adapting 3D model;

4) Additive manufacturing process simulation for obtaining required technological regimes;

5) Medical additive fabrication according to geometric accuracy in required time;

6) Post processing surface finishing, increase strength, accuracy.

\section{Additive manufacturing}

Titanium AM efforts began in 1997 at the Aeromet Corporation which focused on a direct energy deposition (DED) technology for large aerospace components and Arcam AB using its patented electron beam melting (EBM) technology to produce medical components. 
Due to economic reasons, early efforts on metal AM were focused on expensive parts and components of aerospace and medical industry. These efforts on titanium processing were soon followed by other companies such as EOS, Concept Lasers, MTT, SLM Solutions, Sciaky, Solidica, and more.

Table 1 shows a comparison of capabilities, benefits, and limitations of various AM technologies that are used for producing titanium parts today.

Table 1. Comparison of AM technologies

\begin{tabular}{|l|l|l|l|}
\hline Parameter & $\begin{array}{l}\text { Laser Based } \\
\text { (eg, SLM) }\end{array}$ & $\begin{array}{l}\text { Electron Beam Based } \\
\text { (eg, EBM) }\end{array}$ & $\begin{array}{l}\text { Laser Based Directed } \\
\text { Energy Deposition } \\
\text { (eg, DMD) }\end{array}$ \\
\hline Build envelop & Limited & Limited & Large and flexible \\
\hline $\begin{array}{l}\text { Build } \\
\text { capability }\end{array}$ & $\begin{array}{l}\text { Complex geometry, } \\
\text { cellular structure, building } \\
\text { hollow channels }\end{array}$ & $\begin{array}{l}\text { Complex geometry, } \\
\text { cellular structure, } \\
\text { building hollow } \\
\text { channels }\end{array}$ & $\begin{array}{l}\text { Relatively simpler } \\
\text { geometry with less } \\
\text { resolution }\end{array}$ \\
\hline Beam size & $0.1-0.5 \mathrm{~mm}$ & $0.2-1 \mathrm{~mm}$ & can vary from 2 to $4 \mathrm{~mm}$ \\
\hline Layer thickness & $50-100 \mu \mathrm{m}$ & $100 \mu \mathrm{m}$ & $500-1000 \mu \mathrm{m}$ \\
\hline Build rate & $<50 \mathrm{cc} / \mathrm{h}$ & $55-80 \mathrm{cc} / \mathrm{h}$ & $16-320 \mathrm{cc} / \mathrm{h}$ \\
\hline Surface finish & Ra $9 / 12 \mu \mathrm{m}, \mathrm{Rz} 35 / 40 \mu \mathrm{m}$ & Ra $25 / 35 \mu \mathrm{m}$ & $\begin{array}{l}\text { Ra } 20-50 \mu \mathrm{m}, \\
\text { Rz } 150-300 \mu \mathrm{m}, \\
\text { depends on beam size }\end{array}$ \\
\hline Residual stress & High & Minimal & High \\
\hline $\begin{array}{l}\text { Heat } \\
\text { treatment }\end{array}$ & $\begin{array}{l}\text { Stress relief required, HIP } \\
\text { preferred }\end{array}$ & $\begin{array}{l}\text { Stress relief not } \\
\text { required, HIP may or } \\
\text { may not be performed }\end{array}$ & $\begin{array}{l}\text { Stress relief required, } \\
\text { HIP preferred }\end{array}$ \\
\hline
\end{tabular}

Clearly, SLM and EBM technologies provide better surface finish and smaller layer thickness, that's why they are more suitable for more accurate, complex small sized objects, while DMD is more suitable for building relatively larger parts at a high processing rate, but with a coarser finish surface.

\subsection{Selective laser melting}

SLM is a very promising technique due to the intense heat input, avoiding problems such as balling effect, deteriorated surface finish, tensile residual stress, and part distortion. The most important parameters are the laser power, the laser spot diameter, the scanning parameters, such as the scanning velocity, the scanning strategy; and the material properties such as the surface tension, the thermal conductivity, freezing range of the alloy. The chamber environment conditions also play a large role.

Solidification during SLM is characterized by small melt pools $(\approx 100 \mu \mathrm{m})$ and high energy input : high temperature gradient, high growth rate, parts are fully dense $(>99 \%)$, direction of growth of solid/liquid interface can vary from one melt pool to another inside a same grain, good mechanical properties.

\section{The investigation of the mechanical properties of SLM Ti-6AI- 4V samples}

\subsection{Materials and experimental methods}

SLM of a Ti-6Al-4V was carried out in an argon atmosphere employing a SLM280 machine without heating building platform. The size of building platform : $280 \times 280 \times 350$ 
$\mathrm{mm}$. The laser in this study is a continuous Nd:YAG laser. The powder consisted of spherical particles with a size distribution according to the following D-values as measured by laser diffraction: D10 $=30 \mu \mathrm{m}, \mathrm{D} 50=43 \mu \mathrm{m}$ and D90 $=55 \mu \mathrm{m}$. Samples of $10 \times 10 \times$ $70 \mathrm{~mm}^{3}$. The SLM experiments were conducted with a powder layer thickness of $50 \mu \mathrm{m}$.

The mechanical properties of titanium alloy Ti-6Al-4V was investigated on fatigue testing model INSTRON 8802.

\subsection{Results}

Table 2 shows the minimal mechanical properties of titanium alloy Ti-6Al-4V produced by AM 1 (AMS 4999).

Table 2. The mechanical properties of titanium alloy Ti-6Al-4V by AM

\begin{tabular}{|c|c|c|c|c|}
\hline \multicolumn{2}{|c|}{} & \multicolumn{2}{|c|}{ Yield stress $\sigma_{0,2}, \mathrm{MPa}$} & \multirow{2}{*}{$\%$ Elongation } \\
\hline Ultimate strength $\sigma_{\mathrm{B}}, \mathrm{MPa}$ & \multicolumn{2}{|c}{} \\
\hline 896 & Y- \& Z- direction & X-direction & Y- \& Z- direction & \\
\hline
\end{tabular}

Where $\mathrm{X}$ is in the direction of deposition; $\mathrm{Y}$ is transverse to the $\mathrm{X}$ direction and in the plane of deposition; $\mathrm{Z}$ is the direct normal to the plane of deposition. The specification calls for post AM thermal processing, viz., HIP or thermal anneal treatment. The HIP cycle is nominally $100 \mathrm{MPa}$ and $926^{\circ} \mathrm{C}$ for $2-4 \mathrm{~h}$ and furnace cooled below $427{ }^{\circ} \mathrm{C}$. The thermal anneal is nominally $913{ }^{\circ} \mathrm{C}$ for $2-4 \mathrm{~h}$ and furnace cooled below $427^{\circ} \mathrm{C}$. It is worth noting that both the HIP temperature and the thermal anneal temperatures are within the $\alpha-\beta$ phase field close to the $\beta$-transus temperature of $1000^{\circ} \mathrm{C}[15,16]$.

To study the mechanical properties, a batch of cylindrical samples from a Ti-6Al-4V titanium alloy was produced with follow technological parameters (SLM280): a laser power- $225 \mathrm{~W}$, a scan speed $-805 \mathrm{~mm} / \mathrm{s}$ and a hatch step of $0.12 \mathrm{~mm}$. The results of mechanical tensile testing are presented in Table 3 in comparison with the cast and rolled alloy.

Table 3. The mechanical properties of titanium alloy Ti-6Al-4V by different technology

\begin{tabular}{|l|c|c|c|}
\hline \multicolumn{1}{|c|}{ Technology } & Equipment & $\begin{array}{c}\text { Ultimate strength } \boldsymbol{\sigma}_{\mathbf{B}}, \\
\text { MPa }\end{array}$ & \% Elongation \\
\hline $\begin{array}{l}\text { Selective laser melting } \\
\text { (SLM) }\end{array}$ & SLM 280 & 1020 & 12 \\
\hline Rolling & - & $900-1100[17]$ & $8-20[17]$ \\
\hline Stamping & - & $950-1100[17]$ & $10-13[17]$ \\
\hline $\begin{array}{l}\text { Electron-beam melting } \\
\text { (EBM)+HIP + solution } \\
\text { heat treat }\end{array}$ & ARCAM (A2) & $1010[16]$ & $13,9[16]$ \\
\hline $\begin{array}{l}\text { Direct metal laser sintering } \\
\text { (DMLS) }+ \text { HIP }\end{array}$ & EOS (M280) & $946[16]$ & $13,9[16]$ \\
\hline
\end{tabular}




\section{Summary and Conclusions}

Success in implementing AM in the manufacturing industry depends on selection of the right applications. Appropriate applications for AM include a long lead time, complex components, low volume expensive components, weight savings through innovative designs, cost savings in high buy-to-fly ratio parts, cost-effective remanufacturing, customized medical implants, and multimaterial components.

The aerospace industry has long recognized the benefits of high-performance titanium alloys for reducing weight in fuselage structures and aircraft skins, interior appliances, aero engine components, and aircraft landing gears. Ti alloys are used in engine fan blades and discs, front bearing housings, compressor and turbine blades, discs, vanes, and hydraulic tubing. The AM technique is particularly attractive for the aerospace industry because of the high buy-to-fly ratios and low weight.

Titanium alloys have potential for using in manufacture of unique hips and knees mechanical devices. AM typically used for producing the conceptual model for manufacturing as well as medical for the low-cost production of the customised medical model.

The effects of laser powder and material properties on molten pool geometry and temperature gradient in SLM process should be evaluated by mathematical model of a physics-based layer build-up approach coupled with a surface moving heat flux.

The authors acknowledge with gratitude the sponsorship of this work by the Ministry of Education and Science of the Russian Federation (grant № 9.1299.2017 / 4.6).

\section{References}

1. ASTM International. ISO/ASTM Standard 52921-13: Standard Terminology for Additive Manufacturing-Coordinate Systems and Test Methodologies, 2013.

2. G.N. Levy, R. Schindel, J.P. Kruth, CIRP Ann Manuf Technol 52 (2003).

3. J. Holmstrom, J. Partanen, J. Tuomi et al., J. Manuf Technol Manage 21 (2010).

4. W.E. Frazier, Solid freeform fabrication proceedings, $21^{\text {st }}$. international solid freeform fabrication symposium, (2010).

5. F. Caiazzo, F. Cardaropolia, V. Alfieria, V. Sergia, L. Cuccarob, Proc. SPIE 8677 (2012).

6. E. Uhlmanna, R. Kerstinga, T. Borsoi Kleina, |M. Fernando Cruzb, A. Vicente Borillec, Procedia CIRP 35 (2015).

7. Embraer Market Outlook 2009-2028. www-embraer.com.

8. D. Garcia Hernandez, Universitat Politècnica de València, (2014).

9. A.A. Antonysamy, PhD Thesis, The University of Manchester, UK (2012).

10. K. Kiss, J. Wolfe, G. Wilson, D. Abbott, W. Carter, GE jet engine bracket challenge. In grabcad.com/challenges/ge-jet-engine-bracket-challenge.

11. T. Kellner, Next-Gen Materials (2014). Available from: http://www.gereports.com/post/80701924024/fit-to-print.

12. I. Gibson, D. Rosen, B. Stucker, Global Nuclear Safety 3, 20 (2016).

13. G.K. Lewis, R. Nemec, J. Milewski, M. Barbe, Proceedings of the ICALEO'94, Laser Institute of America, Orlando (1994).

14. D.M. Keicher, W.D. Miller, Metal powder report 53, 26 (1998). 
15. E. William, Journal of Materials Engineering and Performance 23, 6 (2014).

16. AMS 4999 Specification, Titanium Alloy Laser Deposited Products 6Al-4V Annealed, SAE, Warrendale, PA 2002

17. V.K. Aleksandrov, N.F. Anoshkin, G.A. Bochvar and etc., Moscow: Metallurgiya (1979).

18. J. Tuomi, K.S. Paloheimo, J. Vehviläinen et al., Surg Innovation 21, 6 (2014) 2014.

19. Mohd. Javaid, Abid Haleem, Alexandria Journal of Medicine (2017). https://doi.org/10.1016/j.ajme.2017.09.003 